\title{
Research on Improvement of TiAIN Coating on Tribological properties of Miniature Inner Grooved Copper Tubes Drawing Mold Materials
}

\author{
Bo $\mathrm{Ma}^{1, \mathrm{a}}$, Bin Liu*1, b, Wei Yuan ${ }^{1, \mathrm{c}}$, Zongtao $\mathrm{Li}^{1, \mathrm{~d}}$ and Fuqiu $\mathrm{Li}^{2, \mathrm{e}}$ \\ ${ }^{1}$ Key Laboratory of Surface Functional Structure Manufacturing of Guangdong High Education \\ Institutes, School of Mechanical and Automotive Engineering, South China University of Technology, \\ Guangzhou 510640, China; \\ ${ }^{2}$ Guangzhou Research Institute of Nonferrous Metals, Guangzhou 510651, China. \\ amabo_mabo@163.com, b380100411@qq.com, ' $249365525 @ q q . c o m,{ }^{d} 1416747471 @ q q . c o m,{ }^{e} 1$ \\ 416149285@qq.com
}

*Corresponding author:Bin Liu, Email:380100411@qq.com

Keywords:TiAIN coating, hard alloy, tribological properties, materials.

\begin{abstract}
The drawing mold of Miniature Inner Grooved Copper Tubes (MIGCT) is made of WC-Co hard alloy, TiAlN coating is deposited on the substrate of WC-Co hard alloy. Inspections on binding force and hardness show that TiAlN coating is provided with fine surface finish and can meet the requirement of industrial production. Under simulated condition, experiments were carried out on the friction between the uncoated/coated hard alloy and copper. The experiments prove that hard alloy with TiAlN coating can effectively decrease the friction coefficient. .
\end{abstract}

\section{Introduction}

MIGCT is an important component of heat-exchange equipment such as air conditioner, etc. With economic development and social progress, the social demand of MIGCT becomes larger and larger, and the MIGCT drawing mold is more widely applied, which results in serious wearing and loss of life of mold, thus the adverse influence is caused on production of MIGCT. Therefore, how to extend the tribological properties of mold to meet ever-growing industrialized production becomes a serious problem at present.

MIGCT is made of copper with 99.95\% copper content through casting, rolling, drawing, annealing, spin forming and reannealing. In the entire drawing and forming process, MIGCT undergoes the maximum deformation at reducing mold where the stress on the mold is also the maximum $^{[1]}$, which results in two consequences: firstly, the most serious abrasion and the shortest service life of the reducing mold; secondly, as MIGCT can never be made of absolutely pure copper, once its $0.05 \%$ impurities present at the external surface of MIGCT, the friction force will be increased due to the contact between the impurities and the mold during drawing, while the increased friction force will probably cause the fracture ${ }^{[2]}$. In view of the fact that MIGCT is drawn under the condition almost close to extreme drawing speed and drawing force in current industry production ${ }^{[3]}$, so a slight decrement of friction force may effectively reduce abrasion and prevent MIGCT from being fractured. Therefore, how to improve the tribological properties of the reducing mold is of great importance. This paper aims at this.

\section{The properties of TiAIN coating}

TiAlN coating is a new superior coating which has emerged in recent dozens of years, which is developed on the basis of TiN[4]. TiAlN coating is provided with mechanical and physical properties which are superior to TiC, TiN and TiCN coatings[5]. It is applicable to the machining of high-speed drawing forming[6]. The superior performance of TiAlN coating benefits from its structure. Adding $\mathrm{Al}$ will not damage the chemical stability of the coating; instead, as the radius of $\mathrm{Al}$ atoms is smaller than the radius of $\mathrm{Ti}$ atoms, $\mathrm{Al}$ atoms can replace $\mathrm{Ti}$ atoms in face-centered cubic crystal structures to distort the crystal structure, so that interplanar crystal spacing will reduce, the number of crystal 
boundaries will increase, and the number of dislocations will increase[7]. As a result, the crystal particles will not prone to sliding, and TiAlN crystal will be formed, which will enable the structure to be more compact, thus effectively increasing the hardness of the coating[8]. This coating is not only provided with stable chemical property, high heat resistance, good abrasion resistance, low friction coefficient and fine film/substrate binding force[9], but also boasts with excellent heat fatigue property, corrosion resistance and oxidation resistance[10]. It is widely applied in machining field, and is a highly praised ultra-hard coating currently. Fig.1 shows TiAlN coating reducing mold with a thickness of $3 \mu \mathrm{m}$.

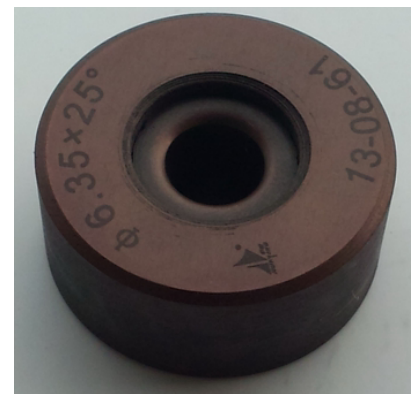

Fig. 1 TiAlN coating reducing mold

\section{Stress analysis of reducing mold}

Thinner tube diameter can effectively save raw materials. Therefore, current mIGCT is developing towards miniature diameter. The most widely applied ones in the market are mIGCT with the outer diameter of $5 \mathrm{~mm}$. For $5 \mathrm{~mm}$ mIGCT, the outer diameter of the mother tube is $7.2 \mathrm{~mm}$, with the wall thickness of $0.32 \mathrm{~mm}$ and surface roughness of $0.02 \mu \mathrm{m}$. Their outer diameter will reduce to $6.35 \mathrm{~mm}$ after passing the reducing mold. The reducing mold used is made of WC-Co hard alloy containing 8\% Co. For research convenience, a sectional view is drawn for the load-carrying condition at the reducing mold as shown in Fig.2. The drawing force is provided on the right, the positions of the reducing mold and the floating plug are fixed. When copper tube passes the reducing mold, the tube diameter will be smaller and the wall thickness will be thinner. In case of theoretical research, when the drawing is stable, the deformation can be divided into 4 stages[11].

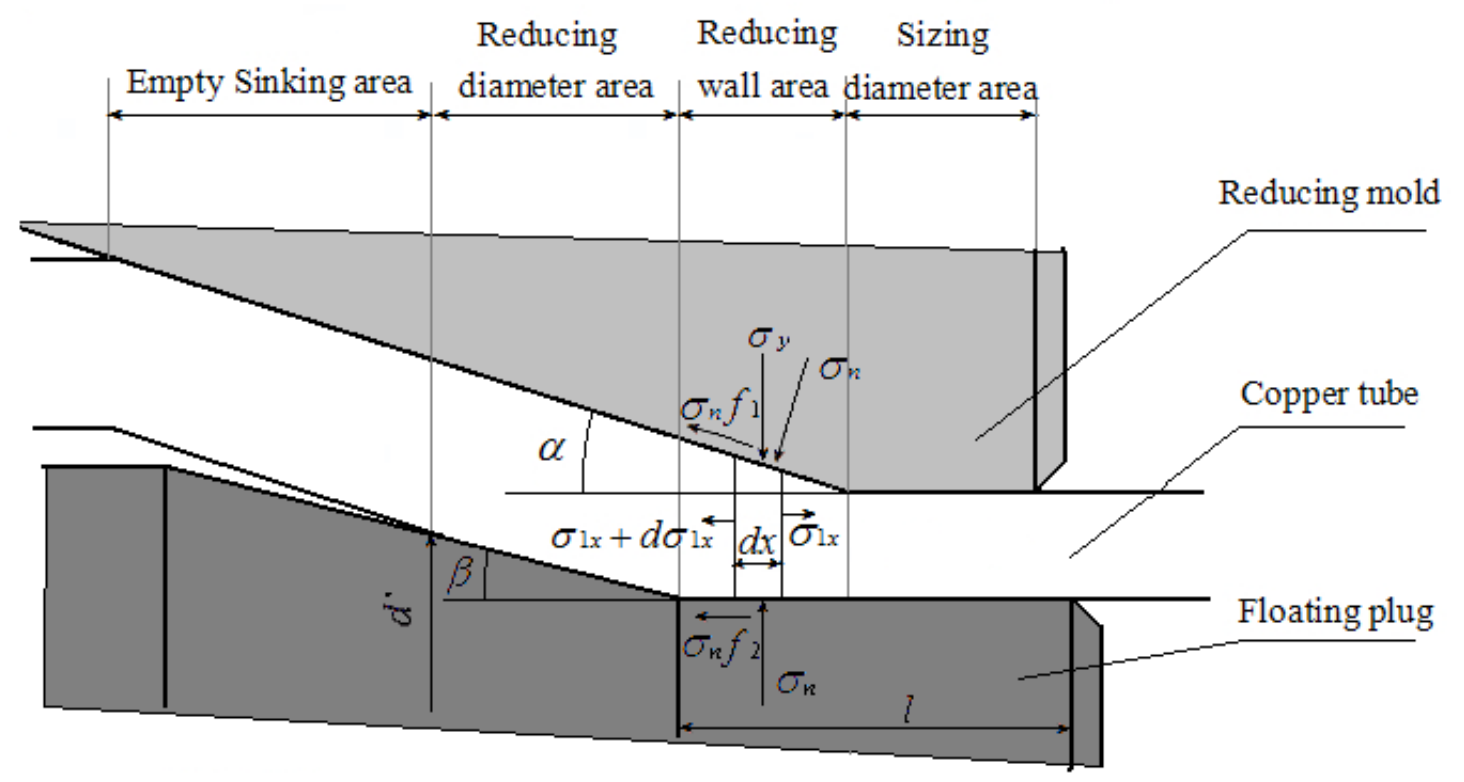

Fig. 2 Features of copper tube deformation area

Stage I: Empty sinking area. In this area, the copper tube contacts with reducing mold, but doesn' t contact with floating plug. 
Stage II: Reducing diameter area. In this area, the inner and outer diameter of copper tube quickly reduce.

Stage III: Reducing wall area. In this area, the inner wall thickness quickly becomes thin.

Stage IV: Sizing diameter area. In this area, the whole deformation process is put in order and stabilized.

The stress of reducing mold at the junction of reducing wall area and sizing diameter area is the maximum[12], which is calculated as follows.

The computational formula for diameter of floating plug at the junction of empty sinking area and reducing diameter area is shown as below:

$$
d^{\prime}=\left[d\left(d+\frac{N_{1}}{N_{2}} l \frac{4 f_{2} \tan \beta}{\tan \beta-f_{2}}\right)\right]^{\frac{1}{2}}
$$

The result is calculated as below:

$$
d^{\prime}=6.01 \mathrm{~mm}
$$

The yield strength of copper related with its working rate; the larger the working rate is, the bigger the yield strength will be. When the copper tubes pass through 4 deformation areas in succession, the working rate gradually increases. Therefore, the value of yield strength from empty sinking area to final sizing diameter area shall gradually increase.

The computational formula for stretching stress of copper tube at elasticoplastic deformation boundary when the copper tube enters into empty sinking area is shown as below:

$\sigma_{1}=(0.15 \sim 0.30) \sigma_{s}$

Then,

$$
\sigma_{1}=0.25 \times 130=32.5 \mathrm{Mpa}
$$

The computational formula for stretching stress working on final fracture surface of empty sinking area is shown as below:

$$
\sigma_{e}=\psi \sigma_{s e} \frac{A}{A-1}\left[1-\left(\frac{D_{e}}{D_{t}}\right)^{A-1}\right]+\sigma_{1}\left(\frac{D_{e}}{D_{t}}\right)^{A-1}
$$

Wherein,

$$
A=\frac{f_{1}+\tan \alpha}{\left(1-f_{1} \tan \alpha\right) \tan \alpha}
$$

The result is calculated as below:

$$
\sigma e=51.72 \mathrm{Mpa}
$$

The computational formula for stretching stress working on final fracture surface of reducing diameter area is shown as below:

$$
\sigma_{r}=1.1 \sigma_{s r} \frac{\varepsilon_{1}}{\varepsilon_{1}-E}\left[1-\left(\frac{F_{2}}{F_{1}}\right)^{\frac{\varepsilon 1}{E}-1}\right]+\sigma_{e}\left(\frac{F_{2}}{F_{1}}\right)^{\frac{\varepsilon_{1}}{E}-1}
$$

Wherein,

$$
\varepsilon_{1}=\frac{B\left(f_{1}+\tan \alpha\right)+\left(f_{2}-\tan \beta\right)}{B \tan \alpha-\tan \beta}
$$

$B=\frac{d^{\prime}+2 S_{1}}{d^{\prime}}$

$E=1-\frac{f_{1} \tan \alpha-f_{2} \tan \beta}{2}$

The result is calculated as below:

$$
\sigma_{r}=65.38 \mathrm{Mpa}
$$

The computational formula for stretching stress working on final fracture surface of reducing wall area is shown as below: 
$\sigma_{w}=1.1 \sigma_{s w} \frac{\varepsilon_{2}}{\varepsilon_{2}-1}\left[1-\left(\frac{F_{3}}{F_{2}}\right)^{\varepsilon_{2}-1}\right]+\sigma_{r}\left(\frac{F_{3}}{F_{2}}\right)^{\varepsilon_{2}-1}$

Wherein,

$$
\varepsilon_{2}=\frac{f_{1}+\tan \alpha}{\left(1-f_{1} \tan \alpha\right) \tan \alpha}+\frac{f_{2}}{\tan \alpha} \frac{d}{D}
$$

The result is calculated as below:

$\sigma_{w}=151.51 \mathrm{Mpa}$

As shown in Fig.2, an infinitely-small annular unit with a thickness of is cut out from the deformed copper tube in reducing wall area, and the stress analysis is made for this unit based on $\mathrm{X}$-axis direction. In order to simplify the calculation, assuming that the positive pressure working on inner and outer wall of copper tube is equal.

The relation between stress of outer surface of copper tube on Y-axis direction and is shown as below:

$\sigma_{y}=\sigma_{n}\left(1-f_{1} \tan \alpha\right)$

Inner surface of copper tube:

$\sigma_{y}^{\prime}=\sigma_{n}$

The average stress is:

$\sigma_{y a}=\frac{1}{2}\left(\sigma_{y}+\sigma^{\prime}{ }_{y}=\sigma_{n}\left(1-\frac{f_{1} \tan \alpha}{2}\right)\right.$

Given

$1-\frac{f_{1} \tan \alpha}{2}=E$

(constant)

The relation between and follows Von Mises yield condition, and it can be expressed as below: $\sigma_{w}+\sigma_{y a}=\psi \sigma_{s}$

The result is:

$$
\sigma_{n}=\frac{\psi \sigma_{s}}{E}-\frac{\sigma_{w}}{E}
$$

The result is calculated as below:

$\sigma_{n}=261.52 \mathrm{Mpa}$

So, the stress at the position where the reducing mold bears the maximum load during the drawing is $261.52 \mathrm{Mpa}$.

\section{Experiments of binding force and hardness of TiAlN coating}

Experiments of binding force of TiAIN coating. The coating may fall in the friction experiment if the binding force of TiAlN coating is too low, thus causing the failure of the experiment[13]. Firstly, its binding force should be tested to avoid this situation. There are many ways to test the binding force of TiAlN coating, of which scratch is simple, practicable and widely used[14]. Therefore, the test is carried out by scratch tester for the binding force of TiAlN coating.

A hemispherical diamond indenter with the diameter of $200 \mu \mathrm{m}$ was pressed on the surface of TiAlN coating mold, with $100 \mathrm{~N}$ load applied on it. Then its surface was moved $1 \mathrm{~mm}$. The microstructure of the scratch was observed under a 400x microscope as shown in Fig.3. The entire scratch was complete with clear profile. TiAlN coating bound well with the substrate, and the coating wasn' t scratched, nor did it peel off. According to the calculation based on the actual contact area between the indenter and TiAlN coating, the stress on the TiAlN coating applied by the indenter is 3183Mpa which is much larger than $261.52 \mathrm{Mpa}$. Therefore, this binding force is sufficient for industrial production. 


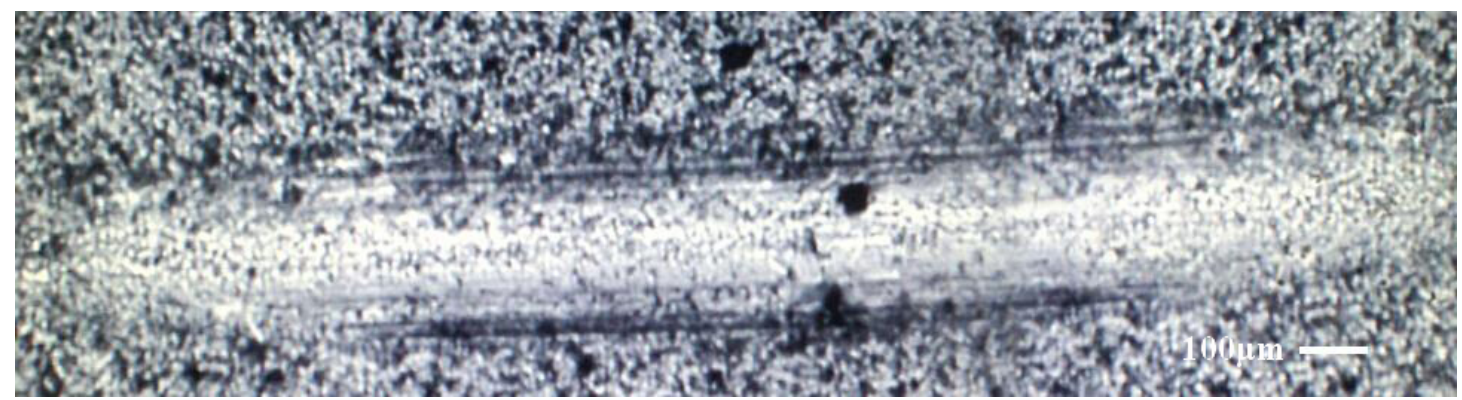

Fig. 3 Microstructure of scratch

Experiments of hardness of TiAlN coating.In view of the sufficient binding force between TiAlN coating and the substrate, it' $\mathrm{s}$ feasible to test its hardness by Vickers hardness tester, and there is no need to worry about the influence of coating peeling on the test result. The pyramidal diamond with square base of the tester was pressed in the surface of the material, and then it was observed under a 1600x microscope. As shown in Fig.4, the red rhombus is the indentation pit left by the forcer on the surface of the material. See Table 1 for the data in the 3 tests, where D1 and D2 are the lengths of the two diagonal lines of the rhombus, for the mean value of these three measurements, its Vickers hardness is 3539.42. The vertex angle of the pyramidal diamond with square base used in the tester is $136^{\circ}$. The calculation was carried out according to the longest diagonal line of the rhombus in the 3 tests, which shows that the depth of the forcer pressed in the TiAlN coating is $1.14 \mu \mathrm{m}$. Therefore, the forcer didn' t contact with the hard alloy substrate. So the test result is the hardness of TiAlN coating, and the substrate hardness has no interference on the result. The hardness of WC-Co hard alloy is 1300, which shows that TiAlN coating significantly improves the hardness of the reducing mold. There are many advantages to apply molds with high hardness to machining. On the one hand, the molds are provided with good abrasion resistance, high durability and long service life[15]; on the other hand, the machined products are provided with good quality, high precision and good smooth finish, which can reduce labor intensity and improve economic performance[16].

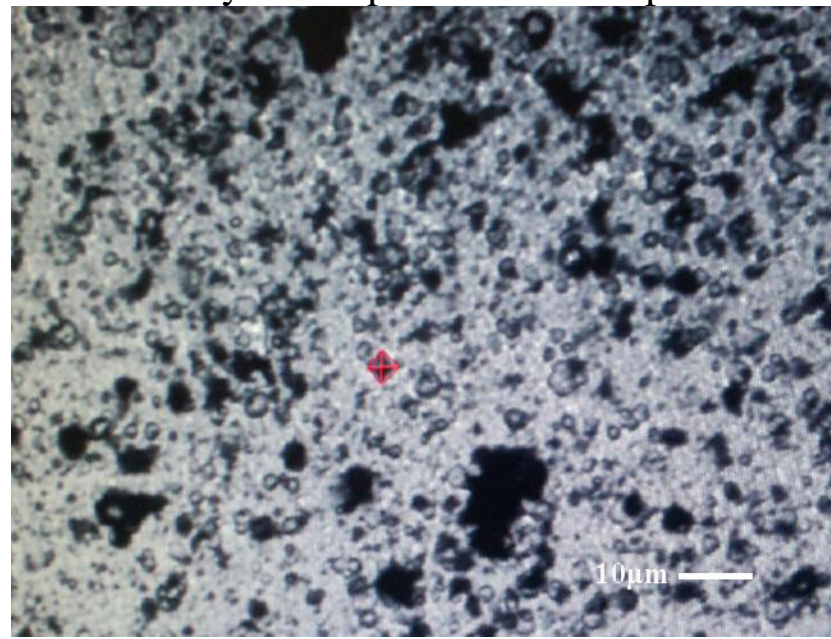

Fig. 4 Microstructure of TiAlN coating

Table 1 Data of hardness test on TiAlN coating

\begin{tabular}{ccc}
\hline D1 $(\mu \mathrm{m})$ & D2 $(\mu \mathrm{m})$ & HV \\
\hline 4.75 & 5.03 & 3877.29 \\
5.16 & 5.65 & 3170.32 \\
4.96 & 5.23 & 3570.65 \\
\hline
\end{tabular}

\section{Friction experiment}

Introduction to experimental instrument.In this experiment, CETR friction-abrasion testing machine is adopted. The CETR friction-abrasion testing machine adopts hardware structure of modularized design, and it is a kind of experimental instrument with complete function, reliable data, and wide application. This testing machine is a testing system which can be applicable for various 
materials, coating, lubricating layer, or research and evaluation on mechanics and tribology features of lubricating oil materials and actual operating condition at nanometer, micro and macro level; the tested samples can be objects of any shape whose size and diameter vary from several nanometers to dozens of centimeters.

The experiment cannot be directly carried out on the testing machine due to reducing mold. Therefore, the experiment was carried out on friction rings which are made of the same material as the reducing mold. Fig.5 shows the articles used in this experiment. Fig.5(a) refers to lubricating oil used for copper tube drawing, Fig.5(b) refers to WC-Co hard alloy friction ring, and Fig.5(c) refers to TiAlN coating hard alloy friction ring which has a same surface roughness with reducing mold, and the surface roughness is $0.02 \mu \mathrm{m}$.

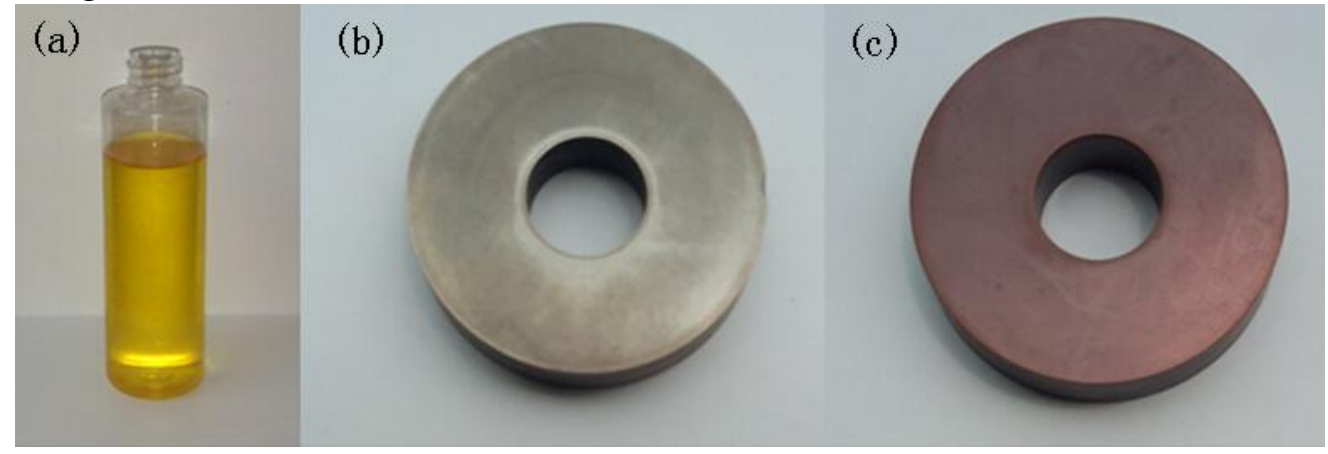

Fig. 5 Experimental articles

Experimental procedure.Fig.6 shows an undergoing friction experiment. The copper pin on the holder installed at the upper part of the friction platform contacts with the friction ring which is rotating at the linear velocity of $0.5 \mathrm{~m} / \mathrm{s}$ (i.e., the friction velocity between the copper tube and the reducing mold under working condition). Lubricating oil is dropped on the friction ring constantly during the experiment to ensure it in complete lubricated status.

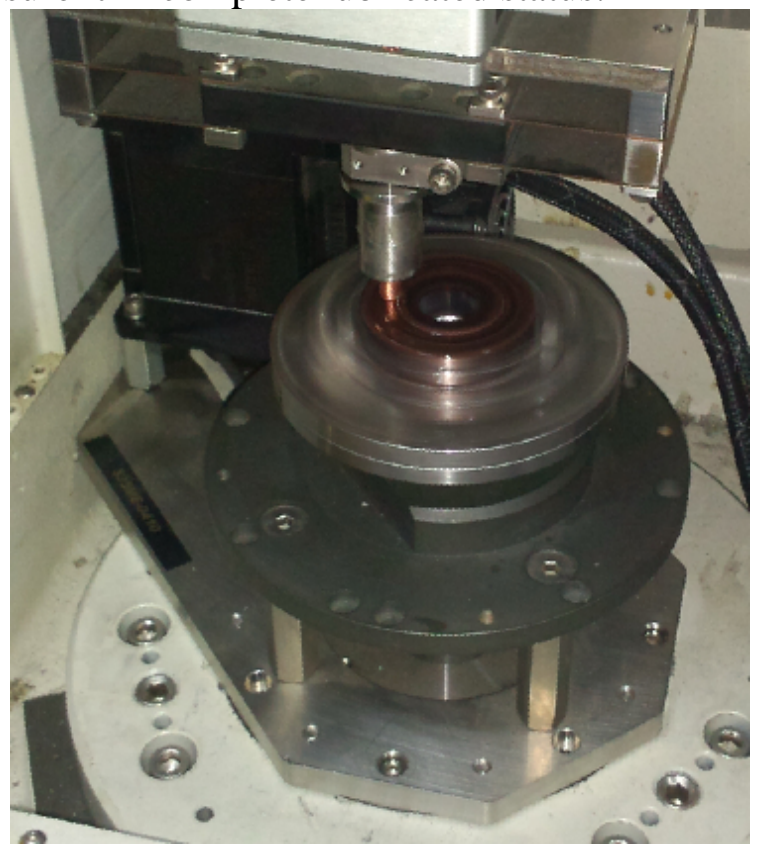

Fig. 6 Friction experiment

Fig.7 and Fig.8 show the friction curves of the two experiments respectively, where Fx is the friction force, and Fz is the load on the friction ring applied by the copper pin. The copper pin may undergo certain abrasion due to friction during the experiment, and it' s impossible for the friction platform to rotate absolutely stably, therefore, the curves may fluctuate within a tiny range. The change rules of the two friction curves are similar. Both friction coefficients are large due to insufficient lubrication at the beginning stage; then there is no fluctuation in the two curves as the friction is in stable stage, with the friction coefficients maintained at a low level. The data during 
stable friction stage were taken to calculate its average value. The friction coefficient between the WC-Co hard alloy friction ring and copper is 0.0145, and the friction coefficient between TiAlN coating friction ring and copper is 0.0132 .

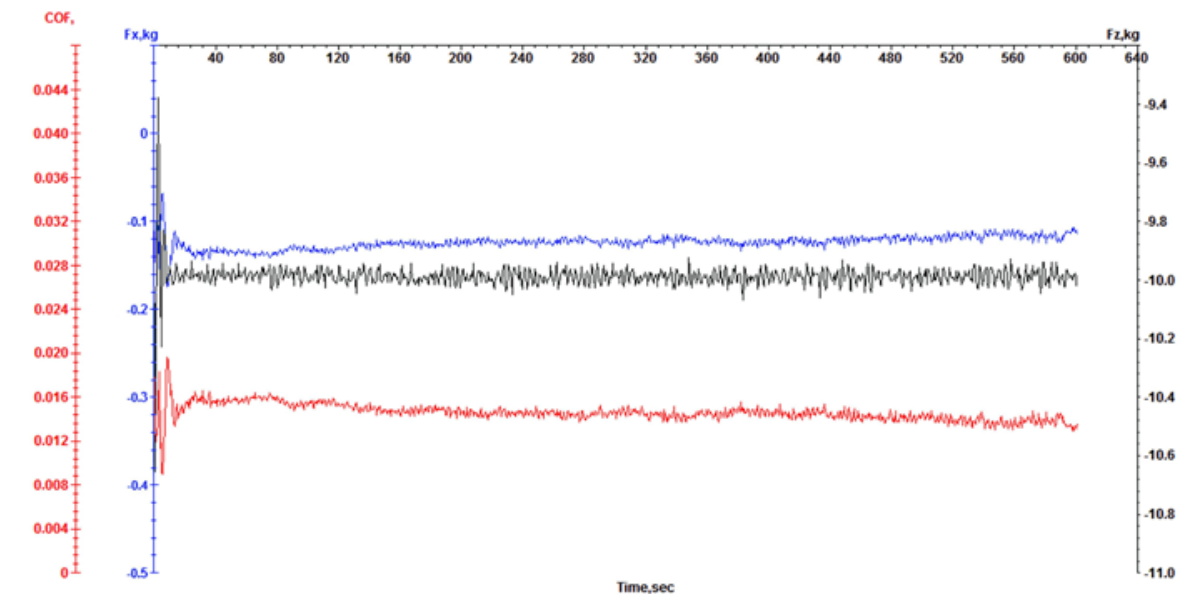

Fig. 7 Friction curve of WC-Co hard alloy friction ring

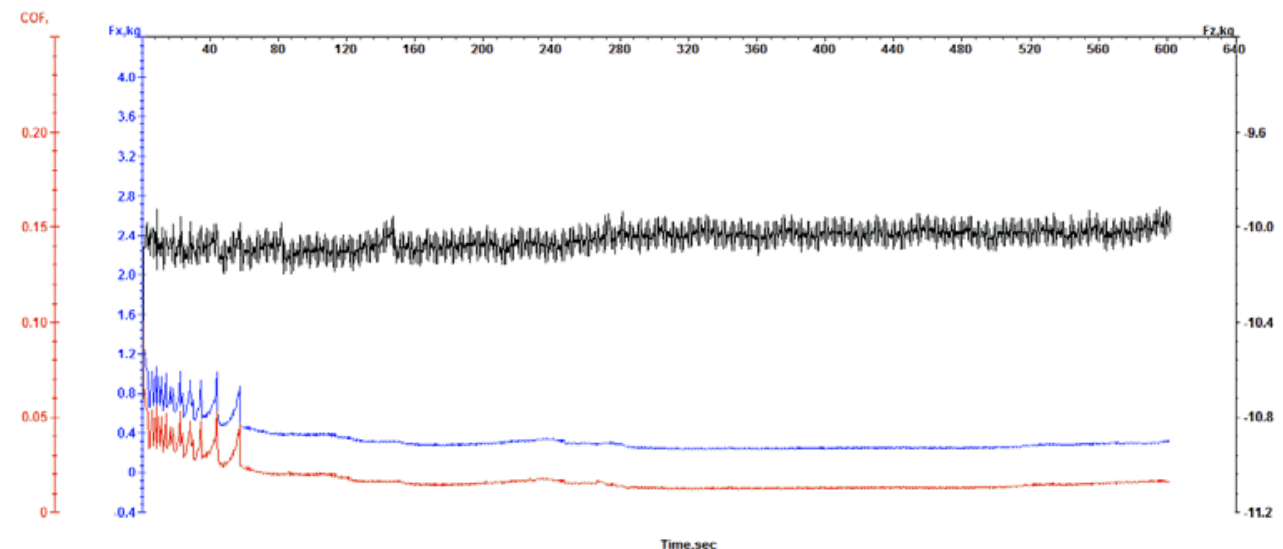

Fig. 8 Friction curve of TiAlN coating hard alloy friction ring

\section{Conclusion}

TiAlN coating is applied on WC-Co hard alloy. Results indicated that:

(1) The performance of TiAlN coating binding force with the substrate is excellent, the hardness of it tested by scratch experiment is also excellent, so TiAlN coating can be widely applied to wear-resistant parts such as drawing mold of mIGCT.

(2)The friction between copper and TiAlN coating hard alloy is 0.0132, which is less than 0.0145, the friction coefficient between copper and WC-Co hard alloy.

Decreased friction coefficient can effective reduce abrasion and reduce the facture of mIGCT. TiAlN coating molds are expected to enjoy broad application prospects.

\section{References}

[1] Y.Tang,Y.Chi,J.Ch.Chen,X.X.Deng,L.Liu,X.K.Liu,Zh.P.Wan.Experimental study of oil-filled high-speed spin forming micro-groove fin-inside tubes.International Journal of Machine Tools \& Manufacture 2007;47,1059 - 1068. 
[2] ZANG Yong, ZHANG Xin-qi, XIE Zhi - wei.Analysis on the influence factors of drawing force in the floating plug drawing process of thin-walled copper tube. Journal of Plast Icity Engineering 2010;Vol.17 No.3, 1007 - 2012.

[3] Yong Tang, Long-sheng Lu, Dong Yuan, Qing-hui Wang, Xiao-lin Zhao. Experimental and FEM study on sinking of miniature inner grooved copper tube. Journal of Materials Processing Technology 2009;209,5333 - 5340.

[4] H.Ohnuma, N.Nihira, A.Mitsuo, K.Toyoda, K.Kubota, T.Aizawa. Effect of aluminum concentration on friction and wear properties of Titanium aluminum nitride films.Surface and Coatings Technology 2004;177 - 178,623 - 626.

[5] ZHENG Liyun,ZHAO Lixin,XIONG Weihao.Tribological properties of TiAlN-coated cermets.Rare Metals 2009;Vol. 28, No. 1, 57-62.

[6] Soon Young Yoon,Seog-Young Yoon,Won-Sub Chung,Kwang Ho Kim. Impact-wear behaviors of TiN and $\mathrm{Ti}-\mathrm{Al}-\mathrm{N}$ coatings on AISI D 2steel and WC - Co substrates.Surface and Coatings Technology 2004;177 - 178, 645 - 650.

[7] Yudong Li,Zhen Liu,Jing Yang,Yigang Chen.Microstructure and properties of (Ti, Al) N coatings on WC-Co hard alloy.Journal of Physics 2013;419,012028.

[8] Liu Aihua,Deng Jianxin,Cui Haibing,Chen Yangyang,Zhao Jun. Friction and wear properties of TiN,TiAlN,AlTiN and CrAlN PVD nitride coatings. Journal of Refractory Metals and Hard Materials 2012;31, $82-88$.

[9] Radhika Ramadoss, N.Kumar, R.Pandian, S.Dash, T.R.Ravindran, D.Arivuoli, A.K.Tyagi. Tribological properties and deformation mechanism of TiAlN coating Sliding with various counterbodies.Tribology International 2013;66, 143 - 149.

[10] S Tanaka, M Takagi,T Mano.Development of Advanced Coating Techniques for Highly-durable Casting Dies.Journal of Physics 2013;Series 417, 12-32.

[11] HUA you-lu. Analysis of the Wear and Friction on the Surface of Carbide Cemented Drawing Die for Copper Tube and Research on Service Life. Master Thesis, Liaoning Technical University,China,2004, 45-88.

[12] Li yaoqun,Yi yinfei. Modern copper coil tube production technology. Metallurgical industry press 2005, 21-80.

[13] Lei Bin.Study on the Tribological Behaviours and Milling Performances of TiAlN Coating.Master Thesis,Southwest Jiaotong University,China,2004,23-47.

[14] Xiahou Liang.The Fabrication and properties of Tantalum Aluminium Nitride Films.Master Thesis.Southwest Jiaotong University,China,2004,69-79.

[15] Wang Gang.A Study of TiAlN Coating Tools.Master Thesis.Changchun University of Science and Technology,China, 2006,12-28.

[16] Lin Yong qing.Surface Properties and Fabrication of Tlaln Films Using Vacuum Arc Ion Plating with Separated Targets. Master Thesis, Harbin Institute of Technology, China, 2007, 25-29. 